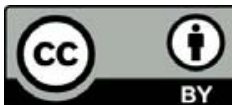

\title{
INTELECTUALIDADE E A CONSTITUIÇÃO DAS (RE)SIGNIFICAÇÕES: A RELIGIOSIDADE POPULAR DO CONTESTADO (1912-1916).
}

\author{
Intellectuality and the construction of (re)significations: the popular religiosity of \\ Contestado (1912-1916).
}

Alexandre Neundorf Doutorando pela Universidade Federal do Paraná, Bolsista CAPES e-mail: alexneundorf@yahoo.com.br

\begin{abstract}
RESUMO: Neste artigo buscamos apresentar uma discussão sobre a relação entre a intelectualidade paranaense, o litigio fronteiriço com o estado catarinense e a construção de um sentido, um significado (ou uma ressignificação), para as populações que habitavam a região contestada pelos dois estados, populações estas marcadamente distintas por uma religiosidade híbrida, miscigenada, sincrética.

Palavras-chave: intelectualidade, intelectuais, identidades, discurso intelectual.
\end{abstract}

ABSTRACT: In this article we present a discussion of the relationship between intellectuality active in the Brazilian state of Paraná, the border dispute with the state of Santa Catarina and building a meaning, a signification (or resignification) for populations that inhabited the region contested by the two states, these populations markedly different by a religious hybrid, mixed, syncretic.

Keywords: intellectuality, intellectuals, identity, intellectual discourse. 


\section{Introdução.}

Já na introdução do seu “A Escrita da História”, Michel de Certeau (2007, p.09) mencionara certas 'armas do sentido', disponíveis, no caso do seu objeto de estudo específico, ao colonizador em contato com o Novo Mundo. Tomando a produção do sentido como resultado da prática discursiva e levando em consideração o valor simbólico que os enunciados adquirem no seu lócus de circulação, o discurso proveniente dos jornais (ou da mídia em geral) revela sua força ao instituir não só o imaginário, mas a própria realidade social, portanto, operando como um 'arsenal simbólico'. Essas mesmas 'armas’ operaram na construção do outro, na região, em guerra, do Contestado. E esse ‘outro’ referenciava-se, entre outros aspectos, em uma religiosidade muito específica e em um imaginário igualmente específico e construído à par dos acontecimentos que se seguiram.

O evento chamado 'Guerra do Contestado', que se desenrolou entre 1912 e 1916 no que hoje são os estados do Paraná e Santa Catarina, delimitou também um tempo de furor discursivo da parte dos intelectuais paranaenses. Estes, através dos suportes localizados nos jornais, procuraram 'contribuir', à sua forma, para a questão que também, uma questão de limites entre os dois estados -, construindo e fazendo circular no meio curitibano o sentido, não só das populações sertanejas do contestado e de suas ações, como da própria região - e através de uma postura que se enquadra dentro de uma matriz ratzeliana. Por meio da análise dos discursos jornalísticos da intelectualidade paranaense, pode-se visualizar a clivagem entre duas 'zonas' - do campo vazio e local do atraso e da bestialidade de suas populações e da cidade, espaço da modernidade e da civilização - e entre seus habitantes - sertanejos 'fanáticos’ versus citadinos 'modernos e civilizados'. Este trabalha buscará enfocar esse referente e também apresentar alguns resultados de pesquisa. ${ }^{1}$

\section{Antecedentes históricos.}

\footnotetext{
${ }^{1}$ Vale mencionar que neste artigo apresentamos apenas uma parte da pesquisa mais aprofundada que desenvolvemos, ao nível do mestrado em História, junto à Universidade Federal do Paraná e que contou com o financiamento da CAPES.
} 
O espaço que hoje compõe o estado paranaense foi motivo de diversos recortes, desde o período colonial até a emancipação política e as querelas fronteiriças com Argentina e Santa Catarina. Porém é somente a partir de meados do século XIX que um novo pensamento é operacionalizado pelos intelectuais e que visa à constituição de recortes espaciais singularizados: é a ideia de região assumindo a sua posição, que irá ocupar no discurso regionalista. ${ }^{2}$

No Paraná, a circunscrição do espaço e sua singularização - pois, construção da região - já poderiam ser vistas no período imperial, ao qual permeava-se um projeto identitário nacional via Instituto Histórico Brasileiro e através da ação de viajantes que se debruçariam sobre estudos regionais. Já na república federativa, a necessária delimitação dos estados faz disseminar em maior escala os discursos regionais, devido ao caráter descentralizado do regime. No Paraná, não é diferente, um movimento regional ancorado em um projeto identitário faz florescer a atividade intelectual que toma como mote principal a questão de limites com Santa Catarina (SZESZ, 1997, p.04) e, posteriormente, a própria 'Guerra do Contestado', uma vez que a definição de litígios fronteiriços deixava de ser questão meramente jurídica para ingressar no campo da política.

A grande maioria das narrativas de defesa da causa paranaense na questão do contestado possui dois aspectos que perpassam suas construções, quais sejam, uma dimensão histórica e um discurso calcado em uma argumentação geográfica acerca dos limites do espaço paranaense. Desse modo, "o discurso geográfico passava a se constituir, assim, em uma das mais importantes fontes para o enquadrinhamento regional do Paraná” (SZESZ, 1997, p.06), mas não só, o discurso histórico também fornecia os elementos para emoldurar e singularizar o espaço, constituindo dessa forma a região. ${ }^{3}$

\footnotetext{
${ }^{2}$ Grosso modo uma região é um território delimitado, cujos marcos acondicionam uma unidade administrativa e jurídica e elementos da paisagem e sociedade característicos e que acabam por singularizar um determinado espaço ante o continuum espacial do qual é um recorte. Sinteticamente, espaço é um lócus delimitado, ou então, o lugar entre dois pontos. O espaço como um meio ideal, uma vez que não é nem uma coisa nem uma sensação, mas uma produção humana. E nesse sentido, instintivamente um espaço é percebido como homogêneo, isótropo, não-contínuo e circunscrito, no caso de uma unidade política como o Paraná, por marcas fronteiriças. Homogêneo, pois se visualiza o espaço como um todo, composto por elementos qualitativamente indistinguíveis - uma vez que a abordagem microrregional é bem posterior ao período estudado; isótropo porque, uma vez que um 'todo', todas as direções e pontos teriam as mesmas propriedades; não-contínuo pois, e em complemento, circunscrito.

${ }^{3}$ Sob uma forma mais refletida e dotada de intencionalidade, o passado irá tomar em Brasil Pinheiro Machado um aspecto primordial na construção de uma ideia de região (MACHADO, 1953).
} 
Da parte dos intelectuais - que passam então a pensar o espaço paranaense enquanto região - é dominante o modelo de região-indivíduo - definida como espaço homogêneo e uniforme, território dotado de características físicas, sociais, econômicas que o tornam individualizado. Esse paradigma norteou as primeiras concepções de região, que, afinal, surgiu no final do século XIX, associado à noção de espaço e sinônimo de região natural. Essa constituiria uma matriz ratzeliana, que defende a ideia de que um conjunto de elementos naturais tais como clima, relevo, vegetação, entre outros, geraria uma singularização de parte do espaço global. Segundo Christiane Marques Szesz, é perceptível, guardado os cuidados em relação à reducionismos, que no Paraná esta matriz foi muito próxima dos intelectuais escrevendo o espaço (SZESZ, 1997, p.08).

A história dos limites cartográficos do Paraná inicia-se na verdade muito antes da constituição do Paraná como província autônoma, da de São Paulo, em 1853. Mesmo na composição das capitanias, no inicio da empresa colonial portuguesa, encontra-se o substrato para a reivindicação posterior do Paraná enquanto espaço autônomo, enquanto uma região, e nesse sentido, enquanto um espaço singular. Uma vez que se percebe a região como produto de um 'corte' espacial - assim como fato ou evento são 'cortes' no tempo (SILVEIRA, 1990, p.20) - pretende-se aqui buscar levantar os diversos momentos em que o espaço territorial, que hoje constitui o Paraná, fora abordado através de construções e desconstruções de delimitação cartográficas (SANTOS, 1988), de ‘cortes’ geográficos, de produção de sentido para o espaço e para as populações que ali se encontravam.

Embora formalmente o Paraná só exista em 1853 com seu desmembramento da província de São Paulo, já durante a política portuguesa de colonização e exploração do território brasileiro que instituíra o sistema de capitanias, o espaço geográfico do hoje Paraná era objeto de manipulações. Inicialmente o litoral norte, uma vez que o interior da região não fazia parte dos domínios portugueses na América pelo tratado de Tordesilhas, fora demarcado como pertencente a capitania de São Vicente; o litoral sul, incluindo parte do que hoje é parte do litoral de Santa Catarina, fazia parte das terras de Santana. Além dessas duas divisões, o ‘todo’ do território brasileiro dividia-se em doze 
zonas lineares de dimensões diversas ${ }^{4}$, onde as 'fatias' mais meridionais - divididas entre Martin Afonso de Souza e seu irmão Pero Lopes de Souza - foram chamadas, de início, capitanias de São Vicente, Santo Amaro e Santana, vindo as duas primeiras a constituírem posteriormente uma única capitania, que confundiria os limites interiores e que acabam tornando-se objeto de litígio entre os seus sucessores no século XVII. Mais a frente, em 1660, o Marques de Cascais, que era um dos herdeiros de Martin Afonso de Souza, com o intuito de consolidar seus direitos sucessórios, cria a capitania de Paranaguá - e que é comprada pela coroa portuguesa em 1711 (LEÃO, 1915, p.06).

À desdém da importância dada às capitanias por seus donatários, assim como os ‘investimentos’ na colonização e exploração do espaço, quer-se aqui e adiante mostrar que desde cedo, o que hoje é o território do Paraná, fora objeto de recorte, de ação que visa delimitar um espaço, de constituir uma territorialidade que garanta e crie as condições simbólicas ${ }^{5}$ - uma vez que contrapõe-se a ideia de um ilimitado desconhecido - para a efetivação de objetivos diversos, relacionados à diferentes tempos e realidades históricas.

Com “o infeliz exito desse regimen” (BARROS, 1877, p.10) - o das capitanias - e um novo pensamento da metrópole, reorganiza-se a colônia sob a imediata direção daquela, fazendo com que as capitanias, que eram transmissíveis por via sucessória, retornem gradualmente à coroa portuguesa. Mas durante o tempo em que se desenrola essa reorganização política na colônia, também se desenvolve, a partir das primeiras povoações do litoral, um processo de irradiação rumo ao interior do território e que viria a extrapolar os limites impostos pelo tratado de Tordesilhas.

No Paraná, a partir de Paranaguá, a transposição da serra do mar rumo ao interior do planalto, acontece já no século XVII, devido à motivação produzida pela

\footnotetext{
4 "Estas capitanias, como todas as mais em que se dividiu o Brazil, tinham limites designados na costa, que era já conhecida, mas não no interior, pelo qual os seos territorios estendiam-se de um modo indefinido, dizendo o régio doador que 'ellas entrariam pelo sertão e terra firme a dentro, tanto quanto pudessem entrar e fossem de sua conquista'” (BARROS, 1877, p 14).

${ }^{5}$ Dois pontos: a) a representação de um espaço através da cartografia e do saber geográfico oferecendo a segurança de um locus simbolicamente 'dominado', pois limitado pela clausura das fronteiras e pelo conhecimento das peculiaridades da terra, assim como propiciando o 'ver' de um espaço de ação e também o 'ver’ de um sentido, não só para o espaço, como para a própria ação no espaço - ação pensada estrategicamente e logisticamente, porquanto repousada em um saber sobre o espaço; b) paradoxalmente em relação ao anterior, a fórmula usada e tão em voga nos tempos coloniais: "entrando pelo sertam e terra dentro tanto quanto puder e for da minha conquista", (LEÃO, 1915, p. 23) que se observa nas provisões da metrópole, mas que oferecem um elemento que insufla o desbravar, a penetração para além dos confinamentos. Um elemento de liberdade, mas também de utopia, pois coadunando com o espírito que visa o desconhecido, local de riqueza em potencial.
} 
descoberta de ouro na região. Essas penetrações, para além dos limites da colônia, permitiram a constituição de inúmeros núcleos populacionais no planalto, cuja ocupação consolida-se com a fundação, em 1690, de São José dos Pinhais, e com vila de Curitiba tornada oficial em 1693.

Outro fluxo de penetração rumo ao interior se dá através das vilas, fundadas por Martim Afonso de Souza, de São Vicente, no litoral do que hoje é o estado de São Paulo, e de Piratininga, já no planalto e consequência da irradiação de populações da primeira. A capitania de São Vicente “[...] veiu a formar o grande foco para a elaboração dos primeiros conquistadores do Brazil”, sendo que o principal centro irradiador consolidar-se-ia no de Piratininga - hoje a cidade de São Paulo -, afinal “elles descubriram e povoaram as mais afastadas regioes do interior, as de Minas Geraes, Goyaz e Matto Grosso”, assim como “de seu seio tambem forma os primeiros povoadores de Santa Catharina e S. Pedro do Sul” (LEÃO, 1915, p.10-1).

Devido em grande parte a sua vanguarda na exploração do interior e ao desenvolvimento de seus núcleos populacionais, assim como, a importância econômica assumida pelas regiões interioranas, em 1710 é constituída a capitania de São Paulo, que então se tornara independente da do Rio de Janeiro. Forma-se desde então “a mais vasta das circumscripções administrativas” que acabam por "apagar o da antiga capitania de S. Vicente”. Essa “desmesurada área” abrangia “[...] não só os territórios confinantes das capitanias de S. Vicente e S. Amaro, excluida a parte que a primeira fornecera para a creação da do Rio de Janeiro, como todos os que haviam descuberto e conquistado os Paulistas ao occidente e ao sul do paiz” (LEÃO, 1915, p.13).

À vastidão do território da capitania de São Paulo, logo se faria a exigência de divisões, devido ao “[...] augmento da população e as crescentes necessidades de seu progresso [...]” (LEÃO, 1915, p.14-5): a formação da capitania de Rio de Janeiro em 1720; a desanexação da Vila de Paraty, incorporada a capitania do Rio de Janeiro, em 1726; em 1738, a desanexação dos territórios da ilha de Santa Catarina e do Rio de São Pedro do Sul, também anexados a capitania do Rio de Janeiro, sendo que no ano seguinte seriam autonomizados e, ainda, posteriormente dividir-se-iam em duas outras capitanias; em 1742 desanexação da Vila de Laguna incorporada ao Rio de Janeiro; a constituição, em 1749, das capitanias de Goyaz e Matto Grosso; e a desanexação da Vila de Lages, incluída na capitania de Santa Catarina, em 1820; finalmente, o 
fracionamento de sua comarca mais meridional - a $5^{\text {a }}$ Comarca de Curytiba - erigindo a província do Paraná em $1853^{6}$. “Após vários desmantelamentos, a capitania de São Paulo foi restabelecida em 1765” (SZESZ, 1997, p.35), quando Paranaguá passa a ser sua $2^{\text {a }}$ Comarca.

Já em relação à vila de Curitiba, seus limites ${ }^{7}$ em 1755, compreendiam o território entre o rio Itararé, confinando com a vila de Sorocaba ao norte, com o rio Pelotas ao sul, com rio Paranapanema, rio Ivaí e campos de Guarapuava ao oeste. Em $1809^{8}$, a definição dos limites nos curso dos rios Paraná e Uruguai.

Com base nos limites meridionais da província de São Paulo, é constituído o argumento chave utilizado pela província, e depois estado, do Paraná durante o desenrolar da querela dos limites com Santa Catarina: o da herança paulista ao Paraná.

Essa herança repousa não só nas fronteiras, fruto da ação desbravadora dos paulistas, mas também no próprio 'povo legendário' - também chamado de 'nova e vigorosa raça', entre outras adjetivações -, como ainda, na própria querela fronteiriça em seu lócus meridional. Uma tríplice 'herança', aqui visualizada, que se compõe de uma prática de clivagem no estabelecimento de fronteiras de exclusão; de uma continuidade heroica, representada pela identidade com o paulista em suas mais extraordinárias qualidades - e que acabam por diferenciá-lo como uma 'raça' singular americana, à qual, no Paraná, viria a se agregar os bens da 'verdade’ e da 'justiça' em momento posterior; de uma busca pela alteridade em um 'outro', cuja encarnação se dará no povo que habita o além das fronteiras à sudeste - onde se visualiza diferentes momentos e também diferentes práticas compondo um sentido para esse 'eles', geralmente vinculadas a uma atitude de negativação.

\section{O discurso intelectual, o discurso político. Os lugares do discurso.}

Um aspecto de importância na caracterização do 'intelectual' em sua especificidade, diz respeito à configuração que assume o discurso por ele proferido:

\footnotetext{
6 Sendo que "assignou-se a esta província a mesma extensão e limites que tinha como comarca pertencente a S. Paulo”. (BARROS, op.cit., p. 15-6). A província do Paraná foi constituída pela lei $\mathrm{n}^{\circ}$ 704, de 29 de agosto de 1853.

${ }^{7}$ Cf. Livro de Veneranças da Câmara Municipal de Curitiba: 1755 (Apud: SZESZ, op.cit., p. 35).

${ }^{8}$ Cf. Carta Régia de $1^{\circ}$ de abril de 1809 (Apud: SZESZ, op.cit., p. 36).
} 
basicamente, na forma com que ele é construído e disposto na sociedade, nas características que ele apresenta e representa.

Primeiramente, a estrutura das narrativas sobre as fronteiras e o problema da identidade, resume-se na linearidade, na expressão das sucessões causais simples, na organização dos eventos 'mais notórios' e 'dotados de importância', na eleição de nomes emblemáticos, na verbosidade e ênfase retóricas, no apelo a uma ‘erudição’ e lastro informacional sobre os documentos referentes aos 'limites históricos’ do Paraná, enfim, na peculiaridade que torna indistinguíveis, discurso intelectual e discurso político.

Nesses discursos, uma peculiaridade seria o conjunto de verdades, apresentadas como inquestionáveis, que são expostas de forma a fornecerem a autorização e legitimação para o intelectual assumi-lo como sua responsabilidade e a sociedade, em contraponto, permitirem-no como seu porta-voz.

Entre os inúmeros aspectos que ressaltam dos discursos intelectuais, alguns possuem uma maior relevância na medida em que revelam características peculiares de como os intelectuais pensavam a sociedade, em outros termos, revelam sua visão de mundo e, até certo ponto, uma visão de mundo partilhada e extensível a toda uma sociedade. Nesse sentido, a figura do pioneiro, o significado da herança, a crença em um futuro luminoso para sua sociedade, a ideia de uma comunidade paranaense, a imagem que construíam de si mesmos, a imagem do Paraná e a imagem da diferença, o sentido de progresso, moderno e civilização, entre outros, são alguns dos assuntos a serem precisados e refletidos.

Na leitura das diversas narrativas não só do período estudado como anteriores, verificamos não só uma falta de ineditismo como uma certa repetição demasiada dos argumentos, em um tributarismo da matriz argumentativa 'fundadora'. A estrutura das narrativas também se oferece com uma espécie de padrão: uma apresentação da situação seguida de um apanhado histórico que remete desde as capitanias hereditárias até a emancipação e a posterior querela com Santa Catarina, concluindo com tons exaltados de defesa da justiça e da verdade. Em outros termos, queremos dizer que o debate oferece pouco refinamento e profundidade reflexiva, baseando-se sobremaneira na qualidade retórica e na eloquência simplesmente. 
A grande maioria das narrativas de defesa da causa paranaense na questão do contestado possui dois aspectos que perpassam suas construções, quais sejam uma dimensão histórica e um discurso calcado em uma argumentação geográfica acerca dos limites do espaço paranaense. Desse modo, “o discurso geográfico passava a se constituir, assim, em uma das mais importantes fontes para o enquadrinhamento regional do Paraná” (SZESZ, 1997, p.06), mas não só, o discurso histórico também fornecia os elementos para emoldurar e singularizar o espaço, constituindo dessa forma a região.

Da mesma forma que todo discurso precisa de uma 'pré-estrutura', também precisa um lugar ‘de onde’ e 'para onde’ se projeta. 'De onde’ retira não só sua legitimidade e autorização, como também a suas próprias condições de materialização. Os diferentes lócus onde se produzem e, efetivamente, se materializam os discursos, possuem também - cada um a sua - forma de operação. E um lugar 'para onde' se dirigem formalmente, ou seja, o lugar que os emissores têm em mente; assim como, os lugares para onde os discursos se difundem sem a intenção formal dos emissores.

No Paraná, os lugares de onde partem os discursos sobre as questões de fronteira e identidade são basicamente de duas ordens: a tribuna das câmaras legislativas ou então as palestras públicas em eventos patrocinados pela política local; e o lugar das narrativas jornalísticas: os periódicos locais e da capital federal principalmente. Embora, a partir de 1912, começasse a surgir outro espaço possível: a Universidade, como evolução do lugar 'cátedra escolar'. A universidade constituiu o espaço que institucionalizou o discurso dos especialistas, tanto do médico e do engenheiro, assumiram a força de verdade entre a elite curitibana a partir do início do século XX (CAMPOS, 2008, p.02-05).

O ambiente literário, já nos fins do século XIX, aparece como o lugar de uma quantidade impressionante de publicações periódicas, sejam jornais, revistas, folhetins, etc. a partir desse momento, “jamais se escreveu tanto; cada escola, cada partido, inclusive cada pessoa tinha seu próprio porta-voz” (NÚÑEZ, 2006, p.01).

\section{O discurso intelectual sobre o espaço.}


Além de sua fala sobre as fronteiras e seu status, 'intelectuais' e políticos também realizaram discursos variados conferindo caráter específico ao espaço que compunha o Paraná. Essa visão, que visava dotar com uma identidade característica o objeto de seu discurso, era também a forma encontrada para legitimar e autorizar a defesa de um 'espaço paranaense', através da via que construíra uma região no estado paranaense, ou seja, um espaço singularizado e dotado de limites precisos.

Um das estratégias (conscientes ou inconscientes) era promover o elogio da natureza em sua prodigalidade, suas riquezas naturais, seu espaço extenso e propício a aventura da exploração e do descobrimento... Um espaço extenso, que:

No meu conceito, era tão urgente elevar á cathegoria de província a $5^{\mathrm{a}}$ comarca de S. Paulo, quanto he indispensável dividir em varias essa antiga comarca. Assim como o governo se S. Paulo encontrava, nas distancias obstáculo quase insuperável aos seus louváveis desígnios, em relação á esta parte de seus governados, acha o juiz de direito da actual comarca no largo espaço que tem de percorrer, ora descendo á marinha, ora subindo para os Campos Geraes, motivo de desanimo e de embaraço ao exacto cumprimento de tantas e tão importantes attribuições, que lhe competem (VASCONCELLOS, 1854, p.07).

De toda forma, os empecilhos de um espaço extenso seriam obliterados pela generosidade com que a natureza dotou não só a qualidade da terra, como de tudo que sobre ela se desenvolvesse:

O aproveitamento de nossas riquezas naturaes e cultura vastíssimas e ferazes terras que possuímos, é problema de cuja solução depende o futuro do Brazil. [...] Possuindo, sobre a maioria dos Estados da União a incomparavel vantagem de um clima temperado admiravelmente propicio ás raças européas, não podia o governo do Estado descurar-se do povoamento do solo, como factor a que directamente se prende o phenomeno da produção (SILVA LIMA, 1907, p.18).

Nessa mesma forma de narrativa que, antes de tudo, visa o elogio (da terra, do povo), quando de sua chegada, Mariana Coelho descreve o Paraná, “cujo conjunto de belezas, em que a Arte e a Natureza se dão amoroso amplexo, fascina e entusiasma os estrangeiros que têm a ventura de a admirar!” (COELHO, 2002, p.20). 
Através das narrativas históricas, contidas nos vários relatos de defesa do Paraná na questão de limites, observa-se a clivagem, ocorrida no momento da emancipação em 1853, entre um passado 'paulista', do qual o Paraná seria o herdeiro inconteste, e um presente 'paranaense', ao mesmo tempo singular, pois portador de 'novas' qualidades, e continuum, na medida em que lega as qualidades do paulista. Desses dois momentos, projetam-se sentidos construídos para o espaço, compostos por diferentes elementos qualificadores. Para o espaço paranaense seria atribuída uma 'personalidade', composta por qualidades abstratas humanas ${ }^{9}$.

Nesse primeiro momento, o espaço geográfico que compunha a comarca de Curitiba até a emancipação paranaense, é percebido e proposto pelos intelectuais como um espaço simbólico, ou melhor, como diferentes espaços que confluem para um aporte, muito positivo em termos qualitativos, à constituição posterior do Paraná. Simbólico porque, por analogia, representa ou substitui outra coisa, qual seja as diversas 'qualidades’ abstratas herdadas do paulista - ou produto do próprio paranaense -, que são impregnadas discursivamente ao espaço por via de alegorias: enfrentamento e o 'vencer' a serra instransponível; a bravura do explorador ante o inóspito desconhecido repleto de “selvagem” e “desumano” (BARROS, op.cit., p.12; LEÃO, op.cit., p.05); a atitude de civilizar um território preenchido por “povos grosseiros” (BARROS, op.cit., p.12-3).

Dessa forma, surge então o espaço da riqueza e da civilização: local onde se descobre minas auríferas, a partir das quais um novo estímulo transmuta uma atitude severa e de cobiça do bandeirante paulista, em relação à preação de índios, em aspirações mais 'dignas' de descoberta de minas e enriquecimento na exploração da terra (BARROS, op.cit., p.12-3); onde o "povo paulistano”, através de "nobres lutas da civilização”, “continua a honrar a pátria”, convertendo os "hábitos hostis e deshumanos dos selvagens” (BARROS, op.cit., p.12-3); desbravando o imenso deserto (BARROS, op.cit., p.10) - não só atribuído pelo vazio populacional, como pela falta de “civilização”. Ao espaço paranaense é atribuída a qualidade de "mudar” a atitude, não só do bandeirante, mas também do selvagem “desumano”.

O espaço da atitude heroica e da aventura: ao ultrapassar a barreira representada pela serra, e que abriga o amedrontador desconhecido, o perigo do

\footnotetext{
${ }^{9}$ Relembramos aqui que o paradigma vigente e que norteia a ação dos intelectuais é o da região-individuo de inspiração ratzeliana.
} 
'selvagem' - tanto homem como animal -, o inóspito da selva e do relevo, além da profundidade ao emaranhar-se no interior do território. Local do "esforço homérico" (BARROS, op.cit., p.11), e nesse sentido, espaço da força, como já o era espaço da coragem, da bravura, da virilidade; local da “excursão aventurosa” (LEÃO, op.cit., p.03), enredo próprio do herói, e espaço da façanha, da iniciativa. Aqui, o espaço paranaense é o lócus onde se desenvolve o heroísmo e a aventura, assim como a força e a coragem.

Com o 'testamento', pois documento que lega a outrem um patrimônio, de 1853, o Paraná constitui-se como província autônoma da de São Paulo; mas não só, esse momento é também o ponto da clivagem, da separação entre o passado herdado e o presente vivido; nesse, opera-se a constituição de um novo sentido para o espaço do Paraná com novos elementos de caracterização e qualificação - somados aos anteriores, uma vez que "aos sacrifícios dos Paulistas e dos que tem continuando a sua obra como Paranaenses!” (BARROS, op.cit., p.72).

Então, o espaço da justiça, na medida em que se luta contra uma “desarrasoada pretensão" de Santa Catarina, que visa "renda locupletando-se com o detrimento do Paraná!”, onde para se vencer a ambição, o recurso à “justiça e a conveniência pública” (BARROS, op.cit., p.79). Também porque se têm que “defendendo o Paraná nada mais faço que servir a justiça” (LEÃO, op.cit., p.02), ao contrário dos “adversos”, que “procurassem somente inspirar-se na Justiça” (LEÃO, op.cit., p.09) e não em iniquidades. A própria decisão final acerca da questão desenrolar-se-ia como um 'erro judiciário’, que a desdém da “justiça da Causa Paranaense” (LEÃO, 1910, p.03), faria desta, causa vencida. Afinal, há um “impulso pró-Justiça” de inspiração na defesa do Paraná ante a questão: “e se cahirmos vencidos, mais nobre mortalha não podemos aspirar do que essa bandeira da Causa Paranaense, que é a própria da causa da Justiça” (LEÃO, 1910, p.15).

E um espaço da verdade, que se retira do recurso à autoridade da "ciência histórica” (LEÃO, 1910, p.02), fornecedora de “sempre uma e sempre insophismavel” verdade (LEÃO, 1910, p.03). Santa Catarina deveria inspirar-se, não só na justiça, como na “verdade histórica” (LEÃO, 1910, p.09), a fim de dirimir tão graves incongruências que habilitam-na a protelar a querela fronteiriça. Já no momento decisório por parte dos juízes do Supremo Tribunal Federal, tem-se que tal atitude em favor do adversário 
estado funda-se não só “contra o Paraná, mas também contra a verdade histórica” (LEÃO, 1910, p.05) a qual o Paraná tanto reclamara.

\begin{abstract}
Banhada, de hum lado pelo Oceano, onde lhe não faltão bons portos, de outro pelo magestoso Paranã, cortada de rios consideráveis, no gozo de hum clima reconhecidamente saudável, com terrenos fertilíssimos, que prestão-se aos mais abundantes e variados productos, tinha a $5^{\mathrm{a}}$ comarca da província de $\mathrm{S}$. Paulo direito e proporções para haver subido á hum elevado gráo na escala dos melhoramentos, que caracterisão a civilisação moderna (VASCONCELLOS, 1854, p.01).
\end{abstract}

Já falando de Curitiba,

Todos reconhecem e confessão a excellencia do seo clima, e o documento mais seguro de sua superioridade fornecem-nos os mesmos habitantes do littoral, todas as vezes (e não são poucas) que, por melhorar de seos padecimentos, sobem a serra e vem pedir aos bellos ares Curityba o restabelecimento de sua saúde arruinada (VASCONCELLOS, 1854, p.01).

\title{
O 'outro’ ou as narrativas de alteridade.
}

É a partir das representações sociais, em circulação na sociedade e construídas com base no senso comum e em um conhecimento prático (conceitos e imagens sobre pessoas e os papéis que elas possuem na sociedade, fenômenos do cotidiano, etc.), que são erigidas e veiculadas imagens negativadas de pessoas e grupos. E é exatamente o processo onde se cria essas imagens que pode ser chamado de 'estigmatização'.

$\mathrm{Na}$ medida em que 'estigmatizar' é construir uma pré-representação negativa sobre algo, podemos afirmar que estigmatizar é também condenar. Desse modo, os atributos ou características que compõe um estigma são pré-avaliados, com pouca ou nenhuma oportunidade de análise crítica e consciente, e que os associe às circunstâncias reais da vida e das relações humanas. Por conseguinte, o estigma (ou preconceito) é inflexível, rígido, imóvel.

Já a partir da emancipação inicia-se um procedimento, embora acreditamos - não deliberado, ou seja, não com uma visão de projeto, que está produzindo e ao mesmo tempo buscando a diferença, a alteridade em uma objetivação 
do 'outro'. Para tanto, a discussão acerca das fronteiras com Santa Catarina assume um status fundamental, pois permite a visualização de um outro para além dos limites paranaenses a sueste. Inicialmente, a busca pela alteridade se dá na observação do catarinense em geral (mas também da província de Santa Catarina como um todo) como a imagem do diferente.

O proceder na produção desse 'outro' se caracteriza na linguagem de descrédito, na negativação das atitudes do estado vizinho, na estigmatização.

Como menciona Bento Fernandes de Barros (1877, p.04):

É para deplorar que Santa Catharina, pondo em acção meios anarchicos, que só exprimem o desespero de causa, pretendesse decidir por si mesma a questão, como se taes meios podessem excluir o seu exame pelo poder competente e mudar a natureza dos factos em que o Paraná funda o seu uti possidetis.

Santa Catarina, além de uma atitude "usurpadora” e "monstruosa" (MACHADO, 1891, p.118), é também “deplorável”, “anarchica” e “desesperada”.

Para frente, continua Barros a tratar sobre a ação dos juízes de Santa Catarina no episódio das barreiras fiscais, a qual qualifica como atitude imprudente e própria para por em perigo a paz pública. Esses juízes são também produtores de “actos tão violentos como insensatos” (BARROS, 1877, p.05), pois:

Simultaneamente expediu o primeiro [juiz municipal do termo de Joinville] um mandado intimando moradores da villa do Rio Negro, e, entre elles, cidadãos mui considerados, para servirem como jurados em Joinville, e o segundo [juiz municipal do termo de São Francisco], uma ordem ao administrador da Agencia fiscal da Encrusilhada, estabelecida, desde 1854, no mesmo município de Rio Negro, para retirar-se, sob pena de ser expellido a força! Insuflada assim a desordem, pelo mesmos juízes que deviam moderar os ânimos e dar o exemplo do respeito às leis, vieram de Joinville, por diversas vezes, grupos armados á Agencia da Encrusilhada, fazendo ao seu administrador incultos e ameaças.

“Esses catarinenses”, objetivados no episódio na figura dos juízes de São Francisco e Joinville, incorporam a imagem ofertada do "outro": produtores da desordem, da anarquia, da imprudência, do desespero de causa, da insensatez. Mas não só, os “advogados de Santa Catarina” são também descritos como executores de 
"sophismas”: "Contra factos eloqüentes como esses, repetimos, são inúteis os sophismas que cavillam os advogados de Santa Catharina” (BARROS, 1877, p.41).

Nessa primeira grande fase, que vai pelo menos até o advento da república quando já se inicia um procedimento deliberadamente projetado e calculado - os esforços concentram-se no estado vizinho como um todo, ou então na objetivação de caracteres em alguns personagens descritos como representantes de Santa Catarina: juízes, força policial, advogados da causa catarinense.

E mesmo posteriormente, é o ‘povo inteiro’ de Santa Catarina mencionado e genericamente tachado de "mentiroso". Povo catarinense que, sempre à custa dos outros que no “sacrifício de plantar povoações, repellindo os selvagens”, quer “aproveitar-se do trabalho alheio" (VASCONCELLOS, 1902, p. 65):

Mentir um povo inteiro, mentir a representação provincial, concordar a presidência da província na mentira, recorrendo-se ao embuste de mandar proceder á eleição de camaras municipaes, dar-lhes posse, approvar posturas e fazer tudo o mais que é próprio dos municípios, sem todavia haver lei que previamente tivesse elevado á Villa os lugares respectivos, foi coisa que nunca se viu, seria a única excepção do "nihil sub sole novum" (VASCONCELLOS, 1902, p. 53).

Ou então, estigmatizar no tempo, em direção ao passado catarinense, uma marca que seria ainda hoje observada:

Muitos illustres paranaenses teem repellido, em luminosos escriptos, as insanas pretenções do visinho Estado que não obstante continuou sempre em sua tarefa de usurpar territórios que nunca lhe pertenceram e a que não tem direito por titulo algum (CLEVE, 1902, p.159). ${ }^{10}$

Já para um segundo momento observado, nessa busca pela alteridade por parte da intelectualidade paranaense, no caso o período marcado pelo conflito do contestado, a angulação do sentido para o ‘outro’ encontra nos ditos ‘invasores’, vindos

\footnotetext{
${ }^{10}$ E continuam pelos anos. Ver: "Os Catharinenses continuam forjando mentiras para comprometter o Paraná”. Jornal Diário da Tarde de Curitiba de 14/01/1916, p. 01; "Um morto... Fanático... com um cheque assignado pelo Sr. Lauro Muller no cano das botas”. Jornal Diário da Tarde de Curitiba de 18/01/1916, p. 01; "Echos de um terrível banditismo". Jornal Diário da Tarde de Curitiba de 18/01/1916, p. 02; “A policia catharinense comette depredações em Timbosinho?”. Jornal Diário da Tarde de Curitiba de 22/01/1916, p. 01; "Editorial: Ela quer ser victima...”. Jornal Diário da Tarde de Curitiba de 24/01/1916, p. 01; “Editorial: A nossa justiça”. Jornal Diário da Tarde de Curitiba de 26/01/1916, p. 01; "Libertemos o Paraná”. Jornal Diário da Tarde de Curitiba de 04/02/1916, p. 01.
} 
de Santa Catarina, a pedra de toque do discurso intelectual - visualizado aqui como a dimensão de um projeto identitário ${ }^{11}$, ou seja, em uma ação planejada e discutida.

A Guerra do Contestado, que foi o conflito social e político que envolveu os estados do Paraná e Santa Catarina entre 1912 e 1916, é na verdade o ápice de uma questão maior, qual seja, a da definição dos limites fronteiriços entre Paraná e Santa Catarina, que se estende no tempo desde antes da constituição da província do Paraná em 1853, ou seja, já entre as províncias de São Paulo e de Santa Catarina. Da movimentação de populações sertanejas do estado de Santa Catarina para o do Paraná visualizou-se - pela intelectualidade paranaense - uma ação de invasão, mas também um momento e um fato propício para se agregar a um projeto de construção identitária regional, na medida em que seria um virtual elemento aglutinador do povo paranaense.

Através do meio jornalístico, intelectuais estabeleceriam o elo entre suas construções discursivas e a sociedade, dessa forma fazendo circular seus enunciados, carregados de valor simbólico, e que direcionavam os sentidos, na maior parte das vezes, negativamente ante os 'invasores’ provenientes do estado vizinho. Partimos aqui de uma constatação simples, mas que nos permitirá desenvolver toda esta parte: das polêmicas ocasionadas pelo conflito do contestado, um personagem emerge como o elemento comum ao discurso dos jornais locais ao longo de todo o período: o homem habitante da região, também chamado sertanejo, caboclo. Porém não é o sertanejo tal qual ele é, mas uma construção do sertanejo oferecida aos moradores da capital pelos intelectuais.

A partir dessa verificação poderia se perguntar o ‘por quê?’ (que seria a questão mais espontânea, instantânea), mas importante também é perguntar o 'como?' se dá essa construção.

Para o primeiro questionamento, resumidamente, ele é parte constitutiva de um discurso que também visa a um projeto identitário. Sendo assim, ele procura um 'outro', um 'eles', condição para um pensar o 'nós' - esse 'outro' figura-se no personagem, ou melhor, na imagem forjada do sertanejo. Mas também porque se quer

\footnotetext{
${ }^{11}$ É conveniente lembrar que, aqui, procuramos diferir 'política' de 'projeto' identitário: para o primeiro, pressupõe-se uma atitude muito mais ampla e envolvente, em uma ação conjunta de diversas instituições e organismos governamentais; para 'projeto', pressupomos uma ação pensada, individual ou coletivamente (através de personagens específicos ou grupos que, sentindo sua necessidade, dispõe-se a objetivá-la), executada através do poder irradiador dos escritos, dos discursos, da notícia, do debate de ideias.
} 
fazer visível e vulgar a imagem desse outro - uma espécie de afirmação identitária através de um recurso a alteridade sempre presente, diária. Mas, além disso, a visibilidade - proporcionada pela confecção de um sentido, de um 'dizer’ o outro oferece também a possibilidade de controle das populações por parte dos governos, pois fornece a possibilidade de um saber sobre o outro. Uma das medidas de controle tomada foi a de expulsar o dito 'invasor’, e isso através de uma ação militar.

Já para o segundo questionamento, quando pergunta-se o 'como?’: o que há é um procedimento que visa escrever o corpo do outro angulando o sentido que se quer para ele. Nessa medida, essa construção de sentido é fruto de um proceder por clivagem - e que já está em operação antes mesmo do conflito -, a uma diferenciação, a uma busca pela alteridade. Esta separação se dá no estabelecer de qualificativos para o outro e, às vezes, para o 'nós' - embora para este último fique subentendido que tudo o que o 'outro' é o paranaense é o oposto em termos positivos, evidentemente.

Compreendemos que a produção do sentido é resultado da prática discursiva e com o valor simbólico que os enunciados adquirem no seu lócus de circulação, o discurso proveniente dos jornais (ou da mídia em geral ${ }^{12}$ ) revela sua força ao instituir não só o imaginário, mas a própria realidade social - nas palavras de Michel de Certeau, através de “as armas do sentido” (CERTEAU, 2007). Afinal, são os meios de comunicação que qualificam os eventos como passíveis à existência pública ou não, assim como o agregam de significado e de interpretações prontas (Ver: WOITOWICZ). Com relação ao nosso estudo, produzem - através de uma forma de violência - o próprio corpo dos seus objetos de enunciação; o corpo do outro, ou seja, escrevem e dão 'o' sentido ao corpo de sertanejo.

Mas também não se pode negar a interferência de determinadas forças sociais agindo na construção da notícia: questões culturais, políticas, econômicas encontram nos jornais o suporte para a sua visão específica da realidade, configurando uma 'colcha de retalhos' de significação, à qual, compete aos intelectuais articular, sob a forma de uma narrativa coerente e consistente. É o jornal, ou melhor, o discurso intelectual atuando nos jornais (ou mesmo na tribuna, nos comícios, nas falas públicas em geral), que 'cola' esses múltiplos discursos sociais, relacionando falas, fatos, opiniões, contexto em uma notícia acabada e que então, em seu processo de circulação,

\footnotetext{
12 Landowski afirma que “o discurso das mídias, evidentemente, cumpre um papel determinante nisso". (LANDOWSKI, 2002, p. 13).
} 
reflui elaborada para o meio de onde parte de seus elementos se originou. Um processo circular, portanto, mas onde a 'força' da influência não age em reciprocidade, pendendo ela para o discurso final dos jornais - afinal, já se tem como parâmetro a própria instituição da imprensa agindo na produção da notícia, através de uma ilusão referencial da linguagem que relacionaria verdade com informação.

Esses discursos reforçam o imaginário social e acabam por fornecer linhasmestras na construção dos sistemas de representação, eles mesmos organizando e forjando imagens e realocando-as no interior de uma dada forma de organização que, na maior parte das vezes, é embasada segundo o formato de pares dicotômicos. Dessa forma as denominações atribuídas aos sertanejos, tais como as de: "Esfaimados carnívoros”; "Bandidos temíveis”; “Bandoleiros assassinos”; “Sanguinários inimigos”; "Feras indignas de piedade"; "Povo inculto e sanguinário"; "Criminosos fanáticos", “infelizes sertanejos transviados” ${ }^{13}$, operam na construção de um sentido altamente pejorativo àquela alteridade, ou "figura do outro".

A mecânica dessa operação é muito simples: a repetição. As notícias que circulam todos os dias trazem a cada edição um novo designativo para essas populações, vez por outra, e em contraponto, enaltecendo também a atitude de algum paranaense partícipe. Para o sertanejo as principais características atribuídas são a do ignorante, do fanático, do rebelde, do criminoso - imagens fabricadas que fazem das narrativas dos intelectuais um campo simbólico que interfere sobremaneira na dimensão social e histórica, assim agindo como fator preponderante na reprodução dos 'consensos' contidos nos jornais e dessa forma forjando um sentido "natural” para a imagem negativizada do sertanejo do contestado.

Já a negativação da religiosidade popular dos sertanejos do contestado, e aqui fazemos uma breve digressão pela historiografia ulterior, também ajudou a concretar uma imagem não só para o monge-messianismo, como para as próprias populações que o seguiam. Por exemplo, na discussão sobre a necessidade de modernização de algumas instituições, em específico, a segurança pública, reivindicavase a necessária construção de uma:

[...] escola de policia methodicamente organisada [...] Ella é um producto e dos mais fecundos da sociologia criminal, que tanto se tem

13 Cf. Jornal Diário da Tarde de Curitiba (iremos tratar posteriormente por DT), respectivamente: 17/06/1915; 12/02/1915; 09/02/1915; 10/10/1914; 02/05/1914; 02/10/1912; 03/06/1912; 12/01/1916. 
empenhado na luta contra o crime. Os processos da anthropologia criminal, há quasi trinta annos vêm mostrando a necessidade da introdução de certa etapa scientifica no exame e nos prejuízos dos factos sujeitos à justiça (VIEIRA, 1912, p.01).

A ressonância desse modo de compreensão persistiria ainda por algum tempo. Já se disse que:

[...] estigmas físicos de degeneração se patenteiam na fisionomia deste segundo 'monge': descontando as características raciais do tipo 'caboclo' - tal o era - os seus lábios são grossos, o nariz grande e achatado, os zigomas salientes, a fronte curta, as orelhas grandes; tipo desempenado, mas baixo e corpulento, a cabeça grande e em desproporção com os membros curtos. [...] o tipo perfeito do fraudador e mistificador, diz-se irmão do 'monge' João Maria ou ser ele mesmo, deixa crescer a barba para impressionar o povo simples e crédulo, impinge-se como profeta; reivindicador, quer restaurar a monarquia. Instintivo, os delitos sexuais estigmatizam a sua moralidade aberrante. Tudo está a caracterizar em José Maria a sua personalidade de degenerado moral (ÁVILA DA LUZ, 1952, p.95).

Ou então que: “[...] se apenas fora desequilibrado e inofensivo no principio, logo passara a ser um perigoso chefe de malta, cujo inicio, no plano inclinado do crime, seria, ao que parece, acobertar crimes dos da sua comitiva” (CARNEIRO, 1942, p.215).

Essa historiografia nada mais é que uma reprise do que já havia sido dito décadas antes, no momento em que o evento se desenrolava, pela intelectualidade paranaense (e também catarinense) nos jornais: voltamos a citar, mas agora as passagens de alguns jornais curitibanos:

Como se não bastasse tanto sangue derramado, a jagunçada tirou, numa emboscada, a vida preciosa do capitão Matos Costa, ilustre e bravo oficial, cujos sentimentos humanitários trazem o mérito de uma pacificação, chamando-se à razão toda essa horda estúpida e alienada que é a dolorosa inferioridade cultural das populações do sertão brasileiro (DT, 19/12/1913).

Pelas informações que chegam daqui e dali e pelo desenrolar dos acontecimentos, o que se nos afigura é que os fanáticos estão unidos por dois elos principais: sua ignorância fanatizada por monges tão ignorantes como eles próprios e seu ódio a algum morubixaba politiqueiro que os tenha molestado por qualquer razão (...). Se são revoltados contra humilhações continuas, se são vítimas da ignorância, 
ou se são ao mesmo tempo uma e outra coisa, merecem esses brasileiros ser acuados na sua toca, como feras, fuzilados a Mouser, varridos a metralha, despedaçados a canhão? Não! Sua culpa é bem menor do que a de quem os exacerbou e de quem os deixou crescer semi-bárbaros nos sertões, segregados da civilização, sem escolas e sem justiça. Que ao menos as intervenções se façam com o mínimo de efusão de sangue exigi-lo0iam os sentimentos de humanidade, se não o impusessem os da justiça. Eles também são brasileiros! (DT, 07/01/1914).

Bandoleiros e assassinos, ou simples espíritos empolgados no negro fanatismo, os seres que, em bandos terríveis de ferocidade se levantaram empunhando armas contra as gloriosas forças do país eram essencialmente prejudiciais à ordem e ao progresso. (DT, 05/04/1915).

Ainda agora, quando tive conhecimento, por telegramma do Exmo. Snr. Coronel Governador de Santa Catharina, de que bandidos reuniam-se de novo em Taquarussú, exactamente como no anno de 1912, alterando a ordem publica n’aquella Estado [...] minha sincera opinião sobre os factos que alli se estavam passando e cuja reproducção periódica é de intuituva previsão, emquanto perdurar entre os dous Estados uma situação que, não obstante a boa vontade de seus governos, annulla a lei nas fronteiras e é propicia a reunião de bandos. (ALBUQUERQUE, 1914, p.16).

\section{Considerações finais.}

Como um arremate parcial para essa discussão, podemos afirmar que a ação do estado (uma ação militar também) no intuito de expulsar o chamado 'invasor' é fruto da pressão exercida pela opinião pública - veiculada em jornais em grande parte - das elites letradas da capital paranaense. Nesses artigos, a insistência nos argumentos que operam uma inferiorização das populações sertanejas, constrói-se uma clivagem entre o 'nós' cultural (representado pelo povo paranaense) e um 'outro' retratado na figura do violento, criminoso e fanático sertanejo.

A reafirmação constante da inferioridade, tanto cultural quanto moral, do sertanejo, acaba por proporcionar uma 'imagem forte' da alteridade - elemento esse visualizado pelos intelectuais como chave para se forjar uma identidade paranaense. À criminoso, o heroico; À fera, o civilizado cidadão; À fanático, o científico; À mentira, a verdade; À iniquidade, a justiça. 


\section{Referências.}

ÁVILA DA LUZ, Aujor. Os Fanáticos: crimes e aberrações da religiosidade dos nossos caboclos. Florianópolis: s.n., 1952.

BARROS, Bento Fernandes de. Discussão da questão de limites entre o Paraná e SantaCatharina. Rio de Janeiro: Dias da Silva Junior, 1877.

CAMPOS, Névio de. Intelectuais paranaenses e as concepções de universidade: 18921938. In: http://www.anped.org.br/reunioes/30ra/trabalhos/GT02-2866--Int.pdf. Acesso em: fevereiro de 2008.

CARNEIRO, David. O Paraná na história militar do Brasil. Curitiba: Tip. João Haupt \& Cia., 1942.

CERTEAU, Michel de. A Escrita da História. 2a Ed. Rio de Janeiro: Forense Universitária, 2007.

CLEVE, Luiz. Limites a Sueste, 1902. In: MARTINS, Romário. Argumentos e Subsídios sobre a Questão de limites entre o Paraná e Santa Catharina. Curitiba: Typ. Impressora Paranaense, 1902.

COELHO, Mariana. O Paraná Mental. 2a Ed. Curitiba: Imprensa Oficial do Paraná, 2002.

Jornal Diário da Tarde de Curitiba: 03/06/1912; 02/10/1912; 19/12/1913; 07/01/1914; 02/05/1914; 10/10/1914; 09/02/1915; 12/02/1915; 05/04/1915; 17/06/1915; 12/01/1916. LANDOWSKI, Eric. Presenças do Outro. São Paulo: Perspectiva, 2002.

LEÃO, Ermelino de. Paraná e Santa Catharina: o voto do Ministro Pedro Lessa. Curitiba: Typ. Cezar Schulz, 1910.

LEÃO, Ermelino de. Paraná - Santa Catharina: O litígio perante a História. Curitiba: Commissão Central de Limites, 1915.

MACHADO, Brasil Pinheiro. Sinopse da história regional. Separata do Boletim do Instituto Histórico. Curitiba: IHGEPR, 1953.

MACHADO, Vicente. Questão de Limites, 1891. In: MARTINS, Romário. Argumentos e Subsídios sobre a Questão de limites entre o Paraná e Santa Catharina. Curitiba: Typ. Impressora Paranaense, 1902.

Mensagem do Governador do Estado: Dr. Carlos Cavalcanti de Albuquerque. Curitiba: Typ. do Diário Official, 1 de fevereiro de 1914. 
NÚÑEZ, Juan Paredes. Paralelos de lo fantástico decadentista. Un caso de proyección de Maupassant en España. Alicante: Biblioteca Virtual Miguel de Cervantes, 2006.

SANTOS, Milton. Espaço e Método. São Paulo: Nobel, 1988.

SILVA LIMA, Vicente Machado. Mensagem ao Congresso Legislativo: dirigida pelo Dr. Vicente Machado da Silva Lima. Curitiba: Annibal Rocha e C., 1 de fevereiro de 1907.

SILVEIRA, Rosa Maria Godoy. Região e História: questão de método. In: SILVA, Marcos A. (Coord.). República em Migalhas - história regional e local. São PauloBrasília: Marco Zero-MCT/CNPq, 1990.

SZESZ, Christiane Marques. A invenção do Paraná: o discurso regional e a definição das fronteiras cartográficas (1889-1920). Dissertação (Mestrado). Universidade Federal do Paraná, 1997.

VASCONCELLOS, Zacarias Goes de. Limites da Provincia do Paraná, pelo lado de S. Catharina, 1857. In: MARTINS, Romário. Argumentos e Subsídios sobre a Questão de limites entre o Paraná e Santa Catharina. Curitiba: Typ. Impressora Paranaense, 1902.

VASCONCELLOS, Zacarias Goes de. Relatório do Presidente da Província do Paraná: O Conselheiro Zacarias de Góes e Vasconcellos. Curitiba: Typ. Paranaense de Candido Martins Lopes, 15 de junho de 1854.

VIEIRA, Ulysses. Segurança Pública. In: Diário da Tarde, 8 de janeiro de 1912.

WOITOWICZ, Karina Lanz. Imagens dos sertanejos na guerra do contestado nas

$\begin{array}{llll}\text { páginas da imprensa. } & \text { In: }\end{array}$

http://reposcom.portcom.intercom.org.br/bitstream/1904/4428/1/NP2WOITOWICZ.pdf . Acesso em: 04/12/2006.

Recebido: 03/04/2012

Received: 04/03/2012

Aprovado: 02/07/2012

Approved: 07/02/2012 